\title{
A Coupled Extraction/Re-Extraction Method for the Chemical Speciation of Nickel in Natural Waters
}

\author{
Carolina Mendiguchía, Cristina Vergel and Carlos Moreno *(i) \\ Department of Analytical Chemistry, Faculty of Marine and Environmental Sciences, University of Cádiz, \\ 11510 Puerto Real (Cádiz), Spain; carolina.mendiguchia@uca.es (C.M.); cristina.vergel@uca.es (C.V.) \\ * Correspondence: carlos.moreno@uca.es
}

Received: 9 December 2019; Accepted: 26 December 2019; Published: 29 December 2019

\begin{abstract}
Chemical fractionation and speciation of metals species in natural waters and its relation with bioavailability have received increased attention in recent years. A simple liquid membranes method, based on coupled liquid extraction and re-extraction processes, is proposed to separate and quantify the species of nickel present in water samples. A simplex optimization of chemical variables, such as carrier concentration in the organic solution and nitric acid concentration in the receiving solution, was performed and, under optimized conditions, the extraction system was applied to determine nickel species in water samples at natural level concentrations. A linear relationship was established between extraction efficacy and the concentration of dissolved organic carbon in the samples, allowing the separation and determination of labile and non-labile nickel fractions, since the latter was not transported through the organic solution acting as liquid membrane. When the total and labile concentrations of metals were analyzed in real samples with different salinities, no significant differences were found between the results obtained and those from well-established methods. An average relative error of 1.50 and 2.37 was obtained for total Ni concentration and labile fraction, respectively. Finally, a comparison with the theoretical speciation data calculated with the software WinHumic V was successfully performed. Thus, the proposed method allows the simultaneous determination of labile and non-labile nickel fractions, presented as a simple alternative to nickel fractionation in natural waters.
\end{abstract}

Keywords: natural waters; extraction; re-extraction; liquid membrane; metals; nickel; speciation; fractionation; labile; non-labile

\section{Introduction}

The presence of trace metals in aquatic systems is a key factor due to the possibility of affecting or even inhibiting some organisms' biological processes when they are above their toxic levels [1-4]. Nevertheless, these effects are mainly related to metal species easily assimilated by the organisms, which are commonly known as labile metal fractions. The separation and quantification of these labile species is an essential issue in order to get a better understanding of trace metals' mobility, reactivity, and toxicity in the environment. Some methods have shown their ability to perform this speciation, mainly using electrochemical approaches [5,6]. However, these techniques focus only on a few elements, mainly $\mathrm{Cu}, \mathrm{Cd}, \mathrm{Pb}$, and $\mathrm{Zn}$. Non-electrochemical techniques, such as absorption, emission spectroscopy or inductively coupled plasma mass spectrometry, usually require a previous step to separate the species. In this context, solid or liquid extraction and diffusive gradient in thin films (DGT) are usually used [7-10].

In the last decades, and based on coupled liquid extraction/re-extraction methods, liquid membranes have appeared as a real alternative to metal separation and speciation in natural waters, since they offer selective transport of different species with an adequate selection of the 
extracting reagent [11-14]. In addition, liquid membranes present other advantages such as high preconcentration factors, reduction of matrix effects, and low sample manipulation [15,16].

Any speciation study requires an operational definition of the species to be used as a reference after separation and/or determination of species [17]. Most researchers tend to compare their results with a well-established analytical method which has shown its applicability for speciation studies $[13,18,19]$, an equilibrium model based on theoretical data of complexes and their stability constants $[5,20-23]$ or both [24,25].

In liquid membranes-based speciation studies, the labile fraction is related to the fraction capable of crossing the membrane and then, it can be considered the bioavailable fraction $[14,26]$. Depending on the experimental setup it can include the free ion or the free ion and mobile and labile metal complexes [27].

In this work a liquid membrane system was applied to the speciation of nickel in real natural waters using an hydrazone derivative, 1,2-cyclohexanedione bis-benzoyl-hydrazone (1,2-CHBBH), dissolved in toluene ( $2 \% \mathrm{~N}, \mathrm{~N}$-dimethylformamid (DMF)). This reagent has previously shown its applicability to separate and quantify nickel fractions in natural water [28]. The results obtained were compared with those obtained from well-established methods as well as with the theoretical speciation data calculated with WinHumic V software.

\section{Materials and Methods}

\subsection{Reagents and Solutions}

Aqueous nickel solutions were prepared using a commercial standard solution of $1000 \mathrm{mg} \cdot \mathrm{L}^{-1}$ purchased from Merck (Darmstadt, Germany). Hydrochloric acid (30\%), nitric acid (65\%), sodium chloride, sodium hydroxide, diethylammonium diethyldithiocarbamate (DDDC), and toluene were obtained from Scharlab (Barcelona, Spain). Hydrogen peroxide $(30 \%)$ and humic acid sodium salt were purchased from Sigma-Aldrich (Steinheim, Germany). A buffer solution was prepared using 4-(2-hydroxyethyl) piperazine- $N^{\prime}$-(2-ethanesulfonic acid) (HEPES) from Biochemical (Barcelona, Spain). N,N-Dimethylformamid (DMF), ethanol (96\%), dimethylglyoxime, ammonium hydroxide $(25 \%)$, ammonium acetate, and chloroform were acquired from Merck. Ammonium pyrrolidine dithiocarbamate (APDC) was purchased from Fluka (Buchs, Switzerland). The active component of the liquid membrane, 1,2-cyclohexanedione bis-benzoylhydrazone (1,2-CHBBH), was synthesized as described previously [29]. All solutions were prepared with deionized water $\left(18 \mathrm{M} \Omega \cdot \mathrm{cm}^{-1}\right)$ from a Milli-Q analytical reagent grade water purification system (Millipore, Bedford, MA, USA).

Synthetic solutions with $100 \mu \mathrm{g} \cdot \mathrm{L}^{-1} \mathrm{Ni}(\mathrm{II})$ and $35 \mathrm{~g} \cdot \mathrm{L}^{-1} \mathrm{NaCl}$ were used as the source phase in optimization experiments. These solutions were buffered at $\mathrm{pH} 8$ using HEPES until a final concentration of $0.25 \mathrm{~mol} \cdot \mathrm{L}^{-1}$ and the appropriate amount of $2 \mathrm{~mol} \cdot \mathrm{L}^{-1}$ sodium hydroxide solution.

\subsection{Apparatus}

Liquid membrane experiments were conducted using a homemade glass beaker-in-a-beaker type cell described elsewhere [30]. It consisted of two concentric beakers containing $730 \mathrm{~mL}$ of sample solution (external beaker) and $12.5 \mathrm{~mL}$ of acidic receiving solution (internal beaker). Aqueous solutions were in contact through an organic solution of 1,2-CHBBH dissolved in toluene ( $2 \%$ DMF) placed over both aqueous solutions, which allows the chemical pumping of nickel ions from the sample to the receiving solution. The volume of organic solution $(100 \mathrm{~mL})$ was chosen to be as small as possible to maximize the transport rate. The solutions were stirred with a magnetic stirrer (JP Selecta, Barcelona, Spain). The nickel extraction process was based on the reaction (1):

$$
\mathrm{Ni}^{2+}{ }_{(\mathrm{ac})}+2 \mathrm{HR}_{(\text {org })} \rightleftarrows \mathrm{NiR}_{2} \text { (org) }+2 \mathrm{H}^{+}{ }_{\text {(ac) }}
$$

where HR represents the extracting reagent 1,2-CHBBH. 
The analysis of nickel in the receiving solution was carried out using an atomic absorption spectrometer Solaar M Series (Thermo Scientific, Waltham, MA, USA). The $\mathrm{pH}$ was controlled by a model 2001-pH meter with a combined glass $\mathrm{Ag} / \mathrm{AgCl}$ electrode (Crison, Barcelona, Spain).

Dissolved organic carbon (DOC) concentrations were determined using a multi N/C 3100 analyzer (Analytic Jena, Jena, Germany). An A705 UV digester (Metrohm, Herisau, Switzerland) was used to destroy organic complexes in the samples when necessary. Blanks and real samples were preconcentrated into a laminar flow hood (Cruma, Barcelona, Spain) located into a class 10,000 Clean Room.

Speciation data were obtained using the WinHumic V software for Win95/98/NT [31].

\subsection{Procedure}

\subsubsection{System Optimization}

The 1,2-CHBBH concentration in the organic solution and the nitric acid in the receiving solution were optimized using the modified simplex method [32]. After defining the variables and step sizes, the initial simplex design was established using the software Multisimplex 2.0.

The dependence of the variables on nickel transport was quantified in terms of mass flux across the membrane measured as permeability coefficient $(P)$ using the Equation (2):

$$
-\ln \left[N i^{2+}\right]=\frac{S}{V_{S}} P t-\ln \left[N i^{2+}\right]_{0}
$$

where $S$ is the effective membrane area, $V s$ is the volume of the source solution, and $\left[\mathrm{Ni}^{2+}\right]_{0}$ and $\left[\mathrm{Ni}^{2+}\right]$ are the nickel concentration in the source solution at time 0 and $t$, respectively.

\subsubsection{Extraction Efficacy}

The extraction efficacy $\left(\mathrm{E}_{\mathrm{e}}\right)$ was calculated as the percentage of nickel transported through the membrane at a certain time. The temporal variation of $\mathrm{E}_{\mathrm{e}}$ was determined using a synthetic solution with $100 \mu \mathrm{g} \cdot \mathrm{L}^{-1} \mathrm{Ni}(\mathrm{II})$ and $35 \mathrm{~g} \cdot \mathrm{L}^{-1} \mathrm{NaCl}$ buffered at $\mathrm{pH} 8$.

Once an extraction time was selected, procedure blanks were performed prior to the study of the influence of organic ligands on $\mathrm{E}_{\mathrm{e}}$. In this sense, preconcentration of deionized water was carried out with the optimized system in order to evaluate the nickel contamination coming from the reagents. Previously, the organic solution was cleaned by solvent extraction with the acidic receiving solution.

Subsequently, the influence of DOC concentration in $\mathrm{E}_{\mathrm{e}}$ was evaluated using a real seawater sample from San Pedro River (Puerto Real, Spain), previously UV digested and spiked with $5 \mu \mathrm{g} \cdot \mathrm{L}^{-1}$ of nickel. Different amounts of humic acid sodium salt were added to the sample to get a DOC concentration from 3.97 to $12.58 \mathrm{mg} \cdot \mathrm{L}^{-1}$. The temporal variation of extraction efficacy in each case was investigated and a relationship between extraction efficacy and DOC concentration was established.

\subsubsection{Application to Real Samples}

The optimized system was applied to separate and quantify labile and non-labile nickel fractions in three real samples from the bay of Cadiz (southwest Spain). The results were compared with those obtained with well-established methods: a solvent extraction with APDC/DDDC and subsequent determination by inductively coupled plasma mass spectrometry (ICP-MS) for total concentration and adsorptive stripping voltammetry (AdSV) without previous UV digestion of the sample for labile fraction [33-35]. A Student's $t$-test was performed to determine if significant differences between the results could be established. In addition, a comparison with the theoretical speciation values from the software WinHumic V was carried out.

Finally, the concentration of free nickel species was calculated using both the theoretical speciation data and the experimental results obtained with the proposed method. 


\section{Results and Discussion}

\subsection{System Optimization}

The results from simplex optimization can be observed in Table 1. After eight experiments the simplex was stopped following the variance criterion [32]. Then, the maximum permeability coefficient was observed at the vertex 6 , with a concentration of $0.89 \mathrm{mmol} \cdot \mathrm{L}^{-1} 1,2-\mathrm{CHBBH}$ in the organic solution and a nitric acid concentration of $1.3 \mathrm{~mol} \cdot \mathrm{L}^{-1}$ in the receiving solution.

Table 1. Simplex optimization of chemical variables.

\begin{tabular}{ccccc}
\hline Vertex & Type & $\begin{array}{c}\text { HCl } \\
\left(\mathbf{m o l} \cdot \mathbf{L}^{-\mathbf{1}}\right)\end{array}$ & $\begin{array}{c}\mathbf{1 , 2 - C H B B H} \\
\left(\mathbf{m m o l} \cdot \mathbf{L}^{-\mathbf{1}}\right)\end{array}$ & $\begin{array}{c}\mathbf{P} \cdot \mathbf{1 0} \mathbf{3}^{\mathbf{3}} \\
\left(\mathbf{c m} \cdot \mathbf{m i n}^{-\mathbf{1}}\right)\end{array}$ \\
\hline 1 & $\mathrm{I}$ & 0.50 & 1.00 & 1.7 \\
2 & $\mathrm{I}$ & 1.00 & 1.00 & 2.5 \\
3 & $\mathrm{I}$ & 0.75 & 1.44 & 2.0 \\
4 & $\mathrm{R}$ & 1.25 & 1.44 & 1.8 \\
5 & $\mathrm{C}$ & 1.06 & 1.33 & 2.9 \\
6 & $\mathrm{R}$ & 1.31 & 0.89 & 2.1 \\
$2^{\prime}$ & $\mathrm{I}$ & 1.00 & 1.00 & 2.0 \\
7 & $\mathrm{R}$ & 1.38 & 1.22 & 1.9 \\
8 & $\mathrm{C}$ & 1.09 & 1.05 & 2.1 \\
$5^{\prime}$ & $\mathrm{R}^{\prime}$ & 1.06 & 1.33 & 1.9 \\
\hline
\end{tabular}

1,2-CHBBH: 1,2-cyclohexanedione bis-benzoyl-hydrazone, I: initial simplex, R: reflexion, C: contraction, P: permeability coefficient.

After the chemical optimization, the stirring rate was increased in order to improve nickel transport through the membrane. Nevertheless, the cell's design avoids the use of stirring rates higher than $500 \mathrm{rpm}$ due to the rupture of organic membrane occurring with the subsequent mixing of aqueous solutions. Then, this stirring rate was selected for the next experiments.

\subsection{Extraction Efficacy}

Temporal variation of extraction efficacy was studied under optimized conditions. As Figure 1 shows, the extraction efficacy increased with the extraction time, although after $9 \mathrm{~h}$ this increase was almost negligible. A control sample after $24 \mathrm{~h}$ showed an extraction efficacy of $35.41 \pm 4.05 \%$, close to the value obtained after $9 \mathrm{~h}(30.15 \pm 1.90 \%)$. Then, an extraction time of $9 \mathrm{~h}$ was selected with the aim of reducing extraction time as much as possible without loss of efficacy. Under these conditions, procedure blanks were performed, obtaining a nickel concentration of $0.41 \pm 0.26 \mu \mathrm{g} \cdot \mathrm{L}^{-1}$ in the receiving solution, low enough to allow the application of the system to real natural waters.

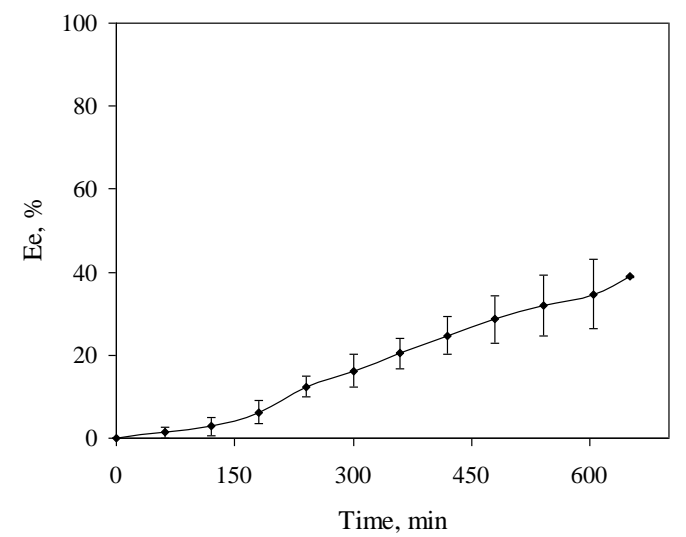

Figure 1. Temporal variation of extraction efficacy. Aqueous solution: $100 \mu \mathrm{g} \cdot \mathrm{L}^{-1} \mathrm{Ni}^{2+}, \mathrm{pH}=8,35 \mathrm{~g} \cdot \mathrm{L}^{-1}$ $\mathrm{NaCl}$. Receiving solution: $1.3 \mathrm{~mol} \cdot \mathrm{L}^{-1} \mathrm{HCl}$. Organic solution: $0.89 \mathrm{mmol} \cdot \mathrm{L}^{-1} 1,2-\mathrm{CHBBH}$. Stirring rate: $500 \mathrm{rpm}$. 


\section{Effect of Dissolved Organic Carbon}

The study of temporal variation in the extraction efficacy was also carried out for a real sample with different DOC concentrations in the range of 0 to $12.58 \mathrm{mg} \cdot \mathrm{L}^{-1}$, added as humic acid. The results are shown in Figure 2, where a decrease of $\mathrm{E}_{\mathrm{e}}$ can be observed with the increase of DOC concentration in the source solution. Nevertheless, temporal behaviour was similar for the different DOC concentrations, allowing the use of an extraction time of $9 \mathrm{~h}$ regardless of the DOC content in the sample. The values of $\mathrm{E}_{\mathrm{e}}$ obtained at this time are shown in Table 2 for each DOC concentration in addition to the theoretical major species distribution. From these data, a negative linear correlation can be established between the experimental values of $\mathrm{E}_{\mathrm{e}}$ and the organic complexes (Ni-HA) formed in the source solution with a Spearman correlation coefficient of -1.0 . These results show the existence of a nickel fraction in the sample related to the organic complex formation, which cannot be transported through the liquid membrane. As a previous work showed, organic nickel complexes remain in the unextracted fraction when 1,2 CHBBH is used to extract nickel in the presence of humic acids [28].

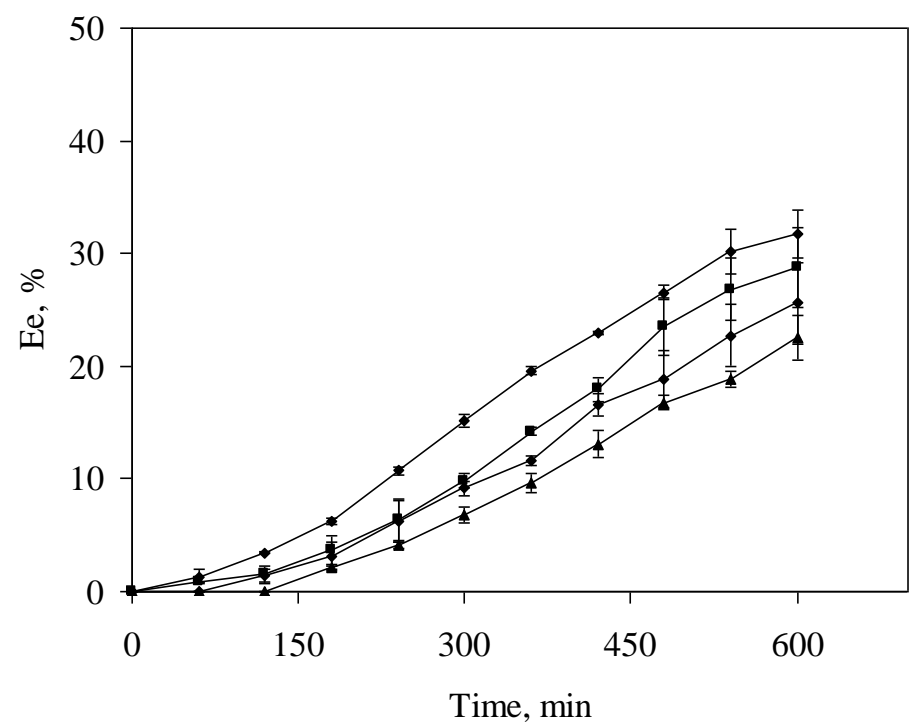

Figure 2. Extraction efficacy dependence on dissolved organic carbon (DOC) concentration.

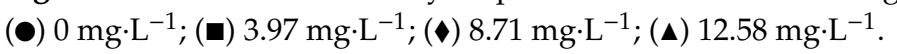

Table 2. Extraction efficacy and theoretical major species distribution depending on DOC concentration.

\begin{tabular}{|c|c|c|c|c|}
\hline $\mathrm{DOC}, \mathrm{mg} \cdot \mathrm{L}^{-1}$ & $E_{e}, \%$ & $\left(\mathrm{Ni}^{2+}\right) \cdot 10^{8}, \mathrm{M}$ & $\left(\mathrm{NiCl}^{+}\right) \cdot 10^{8}, \mathrm{M}$ & $(\mathrm{NiAH}) \cdot 10^{8}, \mathrm{M}$ \\
\hline 0 & $30.15 \pm 1.95$ & 6.34 & 2.13 & 0 \\
\hline 3.97 & $26.82 \pm 0.66$ & 5.46 & 1.84 & 1.18 \\
\hline 8.71 & $22.71 \pm 2.73$ & 4.74 & 1.59 & 2.16 \\
\hline 12.58 & $18.85 \pm 0.75$ & 4.27 & 1.44 & 2.78 \\
\hline
\end{tabular}

In addition, a linear relationship between the $\mathrm{E}_{\mathrm{e}}$ and the DOC concentration could be established by Equation (3):

$$
\mathrm{E}_{\mathrm{e}}=-1.15 \times[\mathrm{DOC}]+30.88
$$

Then, in the presence of organic matter, the extraction efficacy for $9 \mathrm{~h}$ can be calculated for each sample using the DOC concentration, representing the fraction of total nickel transported through the membrane. To validate this relationship between DOC concentration and $\mathrm{E}_{\mathrm{e}}$, analysis of nickel fractions in real water samples was performed. 


\subsection{Application to Real Samples}

Three real samples from the Bay of Cádiz (southwest Spain) were used to study the applicability of the optimized method to determine and quantify the different nickel species present in the samples following the diagram shown in Figure 3. The analysis of a unique subsample allows the determination of the labile and no-labile fraction.

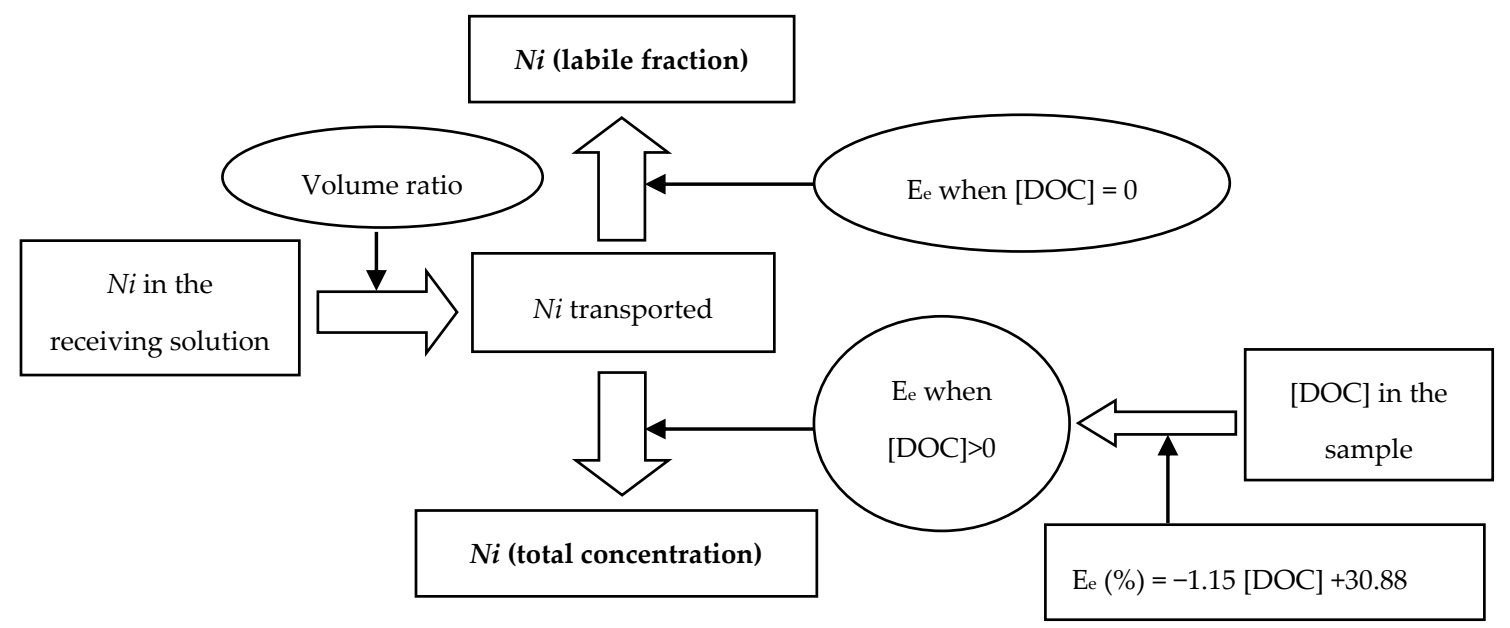

Figure 3. Speciation diagram using the liquid membrane system.

The extraction efficacy obtained in the absence of humic acids (30.15) allows the determination of the labile fraction in the samples, since it represents the percentage of labile nickel which has crossed the membrane. A preconcentration factor $\left(P F_{\text {labile }}\right)$ for labile fraction can be calculated using Equation (4):

$$
P F_{\text {labile }}=\frac{\Delta V \times E e(\text { without ligands })}{100}
$$

where $\Delta V$ is the volume ratio between the two aqueous solution, and Ee(without ligands) is the extraction efficacy when ligands are not presented in the sample. In this case, a value of 17.61 was obtained as $P F_{\text {labile, }}$ which means a concentration on the receiving solution was 17.61 times higher than in the sample.

Then, the extraction efficacy calculated from the DOC concentration using Equation (3) allows the quantification of total nickel concentration in a similar way. Finally, the non-labile fraction may be estimated by the subtraction of total and labile fractions.

The results obtained with this method are shown in Table 3 with those obtained with well-established methods for total and labile fractions. Regardless of the fraction, no significant differences were observed between the two methods for a significant level of 0.05 with an average relative error less than $4 \%$. From these results it is possible to conclude that labile fractions obtained with the liquid membrane system correspond to that determined by AdCSV, including the free nickel ion plus weak inorganic and organic complexes [5]. Then, the non-labile fraction could be related to the stronger organic complexes.

Table 3. Total and labile nickel concentrations in natural water samples.

\begin{tabular}{cccccccc}
\hline \multirow{2}{*}{ Sample } & $\begin{array}{c}\text { DOC } \\
\left(\mathbf{m g} \cdot \mathbf{L}^{-1}\right)\end{array}$ & \multicolumn{3}{c}{ Total Nickel $\left(\mu \mathrm{g} \cdot \mathbf{L}^{-\mathbf{1}}\right)$} & \multicolumn{3}{c}{ Nickel Labile Fraction $\left(\mu \mathrm{g} \cdot \mathbf{L}^{-\mathbf{1}}\right)$} \\
\cline { 3 - 8 } & & $\begin{array}{c}\text { Reference } \\
\text { Method }\end{array}$ & $\begin{array}{c}\text { This } \\
\text { Method }\end{array}$ & $\mathcal{\varepsilon} \mathbf{( \% )}$ & $\begin{array}{c}\text { Reference } \\
\text { Method }\end{array}$ & $\begin{array}{c}\text { This } \\
\text { Method }\end{array}$ & $\varepsilon(\%)$ \\
\hline 1 & 3.11 & $0.73 \pm 0.01$ & $0.73 \pm 0.02$ & 0.00 & $0.65 \pm 0.05$ & $0.66 \pm 0.02$ & 1.54 \\
2 & 3.46 & $1.40 \pm 0.05$ & $1.39 \pm 0.05$ & -0.71 & $1.22 \pm 0.08$ & $1.25 \pm 0.04$ & 2.40 \\
3 & 7.04 & $2.12 \pm 0.16$ & $2.04 \pm 0.08$ & -3.77 & $1.58 \pm 0.24$ & $1.63 \pm 0.07$ & 3.16 \\
\hline
\end{tabular}




\subsection{Comparison with Thermodynamic Speciation Models}

Finally, the labile and non-labile fractions analyzed by the liquid membrane system were compared with the theoretical speciation data from Winhumic V software, which uses model V developed in 1992 by Tipping and Hurley to explain the metal organic complexation in real samples [36]. In this case, the theoretical labile fraction includes the sum of predicted free nickel ion, nickel hydroxides, and nickel chloride complexes, while the non-labile fraction corresponds to organic complexes. As Table 4 shows, there are no significant differences between the experimental and theoretical fractions for saline waters, however high errors were found when freshwater was analyzed. This fact is related to the overestimation of the non-labile fraction when model $\mathrm{V}$ is applied to solutions with low ionic strength and high DOC concentration. In these cases, the counter ion concentration is not enough to compensate the negative charge of humic substances, therefore the majority of nickel ions are expected to form organic nickel complexes [37].

Table 4. Comparison between experimental and theoretical data.

\begin{tabular}{ccccccc}
\hline & Sample & Experimental & Theoretical & $\varepsilon \mathbf{~ ( \% )}$ & $t$ & $t$-Test \\
\hline Labile & 1 & $0.66 \pm 0.02$ & 0.65 & -1.5 & 0.7 & Accepted \\
fraction & 2 & $1.25 \pm 0.04$ & 1.27 & 1.6 & 0.7 & Accepted \\
$\left(\mu \mathrm{g} \cdot \mathrm{L}^{-1}\right)$ & 3 & $1.63 \pm 0.07$ & 0.04 & $>100$ & 32.1 & Rejected \\
\hline Non-labile & 1 & $0.07 \pm 0.01$ & 0.09 & 22.2 & 2.8 & Accepted \\
fraction & 2 & $0.14 \pm 0.05$ & 0.12 & -16.7 & 0.6 & Accepted \\
$\left(\mu \mathrm{g} \cdot \mathrm{L}^{-1}\right)$ & 3 & $0.41 \pm 0.02$ & 2.00 & 79.5 & 112.4 & Rejected \\
\hline \multicolumn{7}{c}{ Critical $t$-value $(\alpha=0.05) ; t_{1}=12.71}$.
\end{tabular}

${ }^{*}$ Critical $t$-value $(\alpha=0.05) ; t_{1}=12.71$.

In addition, the free nickel concentration was estimated in saline waters, calculating a new extraction efficacy for this species under the assumption that only three major species $\left(\mathrm{Ni}^{2+}, \mathrm{NiCl}^{+}\right.$, and Ni-HA) were present in the samples. As Figure 4 shows, the experimental results agreed with theoretical data allowing a good estimation of free nickel concentration.

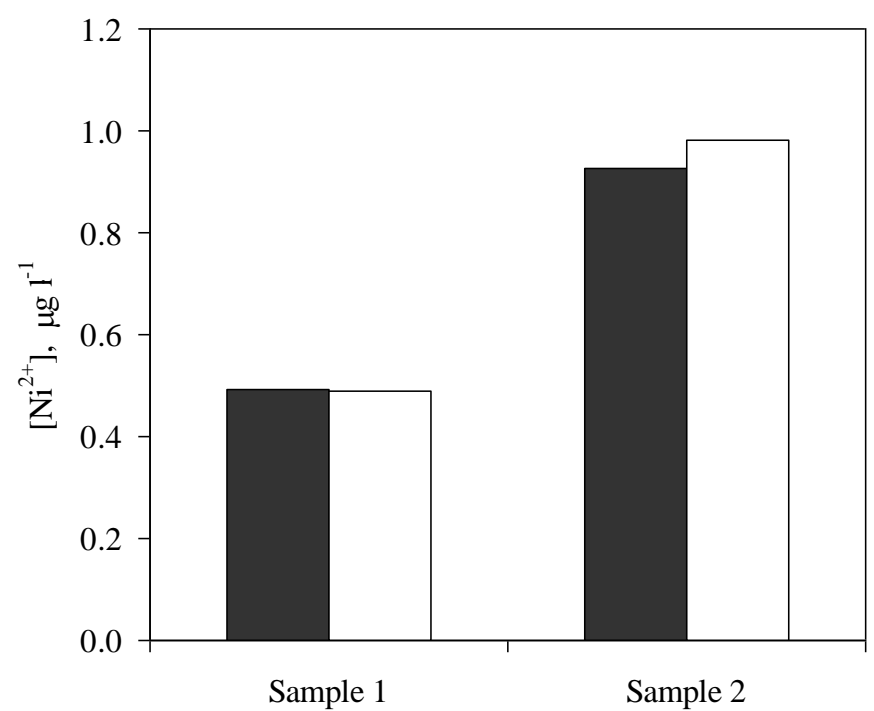

Figure 4. Free nickel concentration in saline waters. (ロ) Experimental data, ( $\square)$ theoretical data.

\section{Conclusions}

A liquid membrane system was developed to perform nickel speciation in natural waters. Under optimum conditions an extraction efficacy of $30.15 \pm 1.90 \%$ was achieved after an extraction time of $9 \mathrm{~h}$ when organic ligands were not present in the sample. A relationship between DOC concentration in the sample and extraction efficacy was established, allowing the simultaneous determination of 
labile and non-labile nickel fractions. The system has been satisfactorily used to determine these fractions in natural waters with different salinities, since significant differences were not found between the results and those from the reference methods. In addition, the results agreed with the theoretical speciation obtained with a thermodynamic speciation model for saline waters although the theoretical model overestimates the labile fraction for freshwater.

Author Contributions: The authors equally participated in the investigation and discussion of the experiments. All authors have read and agreed to the published version of the manuscript.

Funding: This research was funded by Spanish Ministry of Science and Innovation grant number CTM2007-64678-TECNO.

Conflicts of Interest: The authors declare no conflicts of interest.

\section{References}

1. Alhasawi, A.; Auger, C.; Appanna, V.P.; Chahma, M.; Appanna, V.D. Zinc toxicity and ATP production in Pseudomonas fluorescens. J. Appl. Microbiol. 2014, 117, 65-73. [CrossRef] [PubMed]

2. Garceau, N.; Pichaud, N.; Couture, P. Inhibition of goldfish mitochondrial metabolism by in vitro exposure to $\mathrm{Cd}, \mathrm{Cu}$ and Ni. Aquat. Toxicol. 2010, 98, 107-112. [CrossRef] [PubMed]

3. Rodríguez, J.; Mandalunis, P.M. A Review of Metal Exposure and its Effects on Bone Health. J. Toxicol. 2018, 2018, 4854152. [CrossRef] [PubMed]

4. Sreedevi, P.; Suresh, A.; Sivaramakrishna, B.; Prabhavathi, B.; Radhakrishnaiah, K. Bioaccumulation of nickel in the organs of the freshwater fish, Cyprinus carpio, and the freshwater mussel, Lamellidens marginalis, under lethal and sublethal nickel stress. Chemosphere 1992, 24, 29-36. [CrossRef]

5. Martino, M.; Turner, A.; Nimmo, M. Distribution, speciation and particle-water interactions of nickel in the Mersey Estuary, UK. Mar. Chem. 2004, 88, 161-177. [CrossRef]

6. Galceran, J.; Hidobro, C.; Companys, E.; Alberti, G. AGNES: A technique for determining the concentration of free metal ions. The case of $\mathrm{Zn}$ (II) in coastal Mediterranean seawater. Talanta 2007, 71, 1795-1803. [CrossRef]

7. Amourox, D.; Seby, F.; Monperrus, M.; Pannier, F.; Mendiguchía, C.; Benoit-Bonnemason, C.; Donard, O.F.X. Chemical Species. In Chemical Marine Monitoring; Quevauviller, P., Roose, P., Verreet, G., Eds.; Wiley: Chichester, UK, 2011; pp. 101-160.

8. Ding, Y.Y.; Yang, J.H.; Cai, J. Preparation of guanidinylated carboxymethyl chitosan and its application in the diffusive gradients in thin films (DGT) technique for measuring labile trace metals in water. Int. J. Environ. Anal. Chem. 2018, 98, 1275-1291. [CrossRef]

9. Gao, Y.; Zhou, C.Y.; Gaulier, C.; Bratkic, A.; Galceran, J.; Puy, J.; Zhang, H.; Leermakers, M.; Baeyens, W. Labile trace metal concentration measurements in marine environments: From coastal to open ocean areas. TrAC Trends Anal. Chem. 2019, 116, 92-101. [CrossRef]

10. Point, D.; Bareille, G.; Pinaly, H.; Belin, C.; Donard, O.F.X. Multielemental speciation of trace elements in estuarine waters with automated on-site UV photolysis and resin chelation coupled to inductively coupled plasma mass spectrometry. Talanta 2007, 72, 1207-1216. [CrossRef]

11. Chao, J.B.; Zhou, X.X.; Shen, M.H.; Tan, Z.Q.; Liu, R.; Yu, S.J;; Wang, X.W.; Liu, J.F. Speciation Analysis of Labile and Total Silver(I) in Nanosilver Dispersions and Environmental Waters by Hollow Fiber Supported Liquid Membrane Extraction. Environ. Sci. Technol. 2015, 49, 14213-14220. [CrossRef] [PubMed]

12. Mendiguchía, C.; García-Vargas, M.; Moreno, C. Screening of dissolved heavy metals ( $\mathrm{Cu}, \mathrm{Zn}, \mathrm{Mn}, \mathrm{Al}, \mathrm{Cd}, \mathrm{Ni}$, $\mathrm{Pb}$ ) in seawater by a liquid-membrane-ICP-MS approach. Anal. Bioanal. Chem. 2008, 391, 773-778. [CrossRef] [PubMed]

13. Ndungu, K.; Hurst, M.P.; Bruland, K.W. Comparison of copper speciation in estuarine water measured using analytical voltammetry and supported liquid membrane techniques. Environ. Sci. Technol. 2005, 39, 3166-3175. [CrossRef] [PubMed]

14. Vergel, C.; Mendiguchía, C.; Moreno, C. Liquid Membranes as a Tool for Chemical Speciation of Metals in Natural Waters: Organic and Inorganic Complexes of Nickel. Membranes 2018, 8, 19. [CrossRef] [PubMed] 
15. López-López, J.A.; Mendiguchía, C.; Pinto, J.J.; Moreno, C. Liquid membranes for quantification of trace metals in natural waters. TrAC Trends Anal. Chem. 2010, 29, 645-653. [CrossRef]

16. López-López, J.A.; Jönsson, J.A.; García-Vargas, M.; Moreno, C. Simple hollow fiber liquid membrane based pre-concentration of silver for atomic absorption spectrometry. Anal. Met. 2014, 6, 1462-1467. [CrossRef]

17. Templeton, D.M.; Ariese, F.; Cornelis, R.; Danielsson, L.G.; Muntau, H.; Van Leeuwen, H.P.; Lobinski, R. Guidelines for terms related to chemical speciation and fractionation of elements definitions, structural aspects, and methodological approaches (IUPAC Recommendations 2000). Pure Appl. Chem. 2000, 72, 1453-1470. [CrossRef]

18. Twiss, M.R.; Moffett, J.W. Comparison of copper speciation in coastal marine waters measured using analytical voltammetry and diffusion gradient in thin film techniques. Environ. Sci. Technol. 2002, 36, 1061-1068. [CrossRef]

19. Slaveykova, V.I.; Karadjova, I.B.; Karadjov, M.; Tsalev, D.L. Trace metal speciation and bioavailability in surface waters of the black sea coastal area evaluated by HF-PLM and DGT. Environ. Sci. Technol. 2009, 43, 1798-1803. [CrossRef]

20. Doig, L.E.; Liber, K. Nickel speciation in the presence of different sources and fractionations of dissolved organic matter. Ecotoxicol. Environ. Safe. 2007, 66, 169-177. [CrossRef]

21. Zhang, H.; Davison, W. Direct in situ measurements of labile inorganic and organically bound metal species in synthetic solutions and natural waters using diffusive gradients in thin films. Anal. Chem. 2000, 72, 4447-4457. [CrossRef]

22. Romero, R.; Jönson, J.A. Determination of free copper concentrations in natural waters by using supported liquid membrane extraction under equilibrium conditions. Anal. Bioanal. Chem. 2005, 381, 1452-1459. [CrossRef] [PubMed]

23. Gunkel-Grillon, P.; Buffle, J. Speciation of $\mathrm{Cu}(\mathrm{II})$ with a flow-through permeation liquid membrane: Discrimination between free copper, labile and inert $\mathrm{Cu}(\mathrm{II})$ complexes, under natural water conditions. Analyst 2008, 133, 954-961. [CrossRef] [PubMed]

24. Zhang, H.; Davison, W. In situ speciation measurements. Using diffusive gradients in thin films (DGT) to determine inorganically and organically complexed metals. Pure Appl. Chem. 2001, 73, 9-15. [CrossRef]

25. Bayen, S.; Worms, I.; Parthasarathy, N.; Wilkinson, K.; Buffle, J. Cadmium bioavailability and speciation using the permeation liquid membrane. Anal. Chim. Acta 2006, 575, 267-273. [CrossRef] [PubMed]

26. López-López, J.A.; García-Vargas, M.; Moreno, C. A new analytical method for selective pre-concentration of free silver in estuarine waters using liquid membranes. Talanta 2013, 108, 7-10. [CrossRef] [PubMed]

27. Bayen, S.; Wilkinson, K.J.; Buffle, J. Permeation liquid membrane as a sensor of free nickel ion in aqueous samples. Analyst 2007, 132, 262-267. [CrossRef] [PubMed]

28. Vergel, C.; Mendiguchía, C.; García-Vargas, M.; Moreno, C. Quantification of Free and Bound Fractions of Nickel in Natural Waters by Solvent Extraction with 1,2-Cyclohexanedione Bis-Benzoyl-Hydrazone. Solvent Extr. Ion Exch. 2010, 28, 625-635. [CrossRef]

29. García-Vargas, M.; Trevilla, S.; Milla, M. Synthesis and Characterization of 1,2-cyclohexanedione bis-Benzoylhydrazone and Its Application to the Determination of Ti in minerals and rocks. Talanta 1986, 33, 209-214. [CrossRef]

30. Mendiguchía, C.; Moreno, C.; García-Vargas, M. Separation of heavy metals in seawater by liquid membranes: Preconcentration of copper. Sep. Sci. Technol. 2002, 37, 2337-2351. [CrossRef]

31. WinHumicV for Win95/98/NT. Available online: https://www.kth.se/seed/tidigare-avdelningar/lwr/grupper/ vara-datorprogram/winhumicv-for-win95-98-nt-1.635600 (accessed on 4 December 2019).

32. Bayne, C.K.; Rubin, I.B. Practical Experiments Design and Optimization Methods for Chemist; VHC Publishers Inc.: Deerfield Beach, FL, USA, 1986; pp. 128-144.

33. Turner, A.; Nimmo, M.; Thuresson, K.A. Speciation and sorptive behaviour of nickel in an organic-rich estuary (Beaulieu, UK). Mar. Chem. 1998, 63, 105-118. [CrossRef]

34. van den Berg, C.M.G.; Nimmo, M. Determination of interactions of nickel with dissolved organic material in seawater using cathodic stripping voltammetry. Sci. Tot. Environ. 1987, 60, 185-195. [CrossRef] 
35. Metrohm Application Notes. Nickel and Cobalt in Seawater. VA Application Note No. V-69. Available online: https://www.metrohm.com/en/applications/AN-V-069 (accessed on 4 December 2019).

36. Tipping, E.; Hurley, M.A. A unifying model of cation binding by humic substances. Geochim. Cosmochim. Acta 1992, 56, 3627-3641. [CrossRef]

37. Tipping, E. Cation Binding by Humic Substances; Cambridge University Press: Cambridge, UK, 2002; pp. 262-333.

(c) (1)

(C) 2019 by the authors. Licensee MDPI, Basel, Switzerland. This article is an open access article distributed under the terms and conditions of the Creative Commons Attribution (CC BY) license (http://creativecommons.org/licenses/by/4.0/). 